\title{
Ectrodactyly: A rare anomaly of limbs
}

\author{
Keyal K${ }^{1}$, Joshi $\mathbf{B G}^{2}$, Pandey $\mathbf{R}^{3}$, Shrestha $\mathbf{B M}^{4}$ \\ ${ }^{1}$ Dr.Kabita Keyal, MBBS, MD Paediatrics, Registrar Department of Paediatric Medicine, Civil Service Hospital of Nepal, \\ ${ }^{2}$ Dr.Binita Gurubacharya Joshi,MBBS, MD Paediatrics, Registrar Department of Paediatric Medicine Civil Service \\ Hospital of Nepal, ${ }^{3}$ Dr. Rajesh Pandey, MBBS, Medical Officer, Department of Paediatric Medicine Civil Service Hospital \\ of Nepal, ${ }^{4}$ Dr. Binod Man Shrestha, MBBS. DCH. MD. Professor in Paediatrics, National Academy of Medical Science \\ (NAMS), Kathmandu, Nepal.
}

Address for correspondence: Dr. Kabita Keyal, E-mail: kabitakey@yahoo.com

\begin{abstract}
Split-hand/split-foot malformation (SHFM) is a rare congenital malformation of the limbs with median clefts of the hands and feet and aplasia/hypoplasia of the phalanges, metacarpals and metatarsals. When present as an isolated anomaly, it is usually inherited as an autosomal dominant form. We report a case of nonsyndromic form of ectrodactyly because of its rarity.
\end{abstract}

Key words: Split-hand/split-foot malformation, Nonsyndromic ectrodactyly

\section{Introduction}

SHFM or Ectrodactyly, is a rare congenital limb malformation presenting with deficiency or absence of one or more central digits of hand and foot along with/ without syndactyly, median clefts of the hands and feet and aplasia/or hypoplasia of the phalanges, metacarpals and metatarsals. There is a median cleft in the hand and feet due to the absence of the central digital rays, which gives the appearance of a lobster, hence is also referred to as Lobster- claw syndrome.

Two modes of expression exist for SHFM, including an isolated nonsyndromic form limited just to the limbs and syndromic expression involving other associated anomalies. The most common mode of inheritance is autosomal dominant while autosomal recessive and X-linked forms also occur but rarely. Our case is a nonsyndromic type of SHFM, as there is no associated anomaly.

\section{The Case}

A 14 months old male child was brought to the pediatric OPD with the complaints of deformed hands and foot since birth and contracture of right ring finger since 6 months. On detailed history patient was the only child, born to a nonconsanguinous parents with no perinatal or postnatal complications. His developmental milestones were normal for his age with no significant past history.

But his father had similar deformity of all the four limbs since birth and was living a normal life. There was no similar history in any of the relatives of both the parents.

On examination: The vital parameters were stable and no abnormalities in the ENT. Anthropometry: Weight on $5^{\text {th }}$ percentile, height and head circumference was on $25^{\text {th }}$ percentile according to NCHS chart. There was no dysmorphic features. Physical and Systemic examination were normal except musculoskeletal system which revealed the absence of index and middle fingers in both the upper limbs and absence of $2^{\text {nd }}$ and $3^{\text {rd }}$ toe in both the lower limbs. There was a flexion deformity of the right ring finger (Fig 1, 2, 3).

X-Ray of the right hand showed presence of capitate and hamate and absence of $2^{\text {nd }}$ and $3^{\text {rd }}$ metacarpal. Index and middle fingers were absent. X-Ray of the left hand showed presence of capitate, hamate and all the five metacarpals. $2^{\text {nd }}$ proximal phalynx was present but deviated towards the thumb and presence of $3^{\text {rd }}$ proximal phalynx with deviation towards the ring finger. The index and middle finger were absent (Fig-4). 


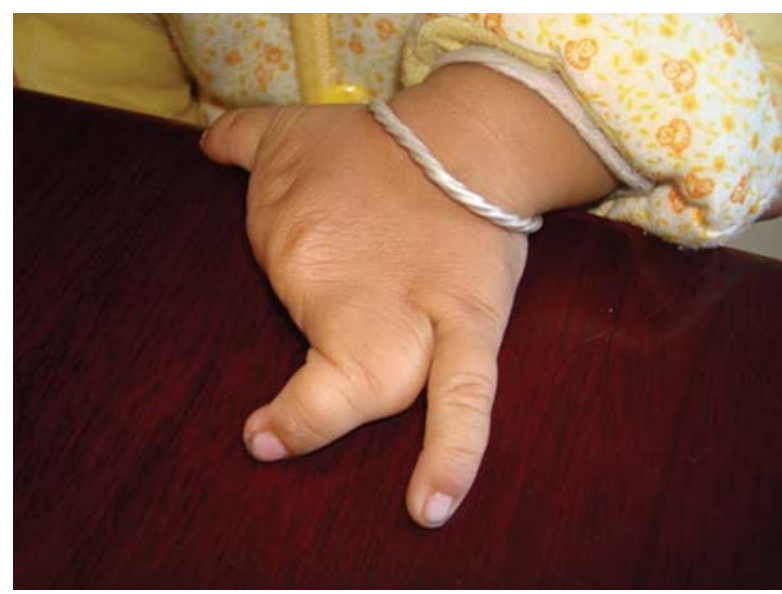

Fig 1: Left hand

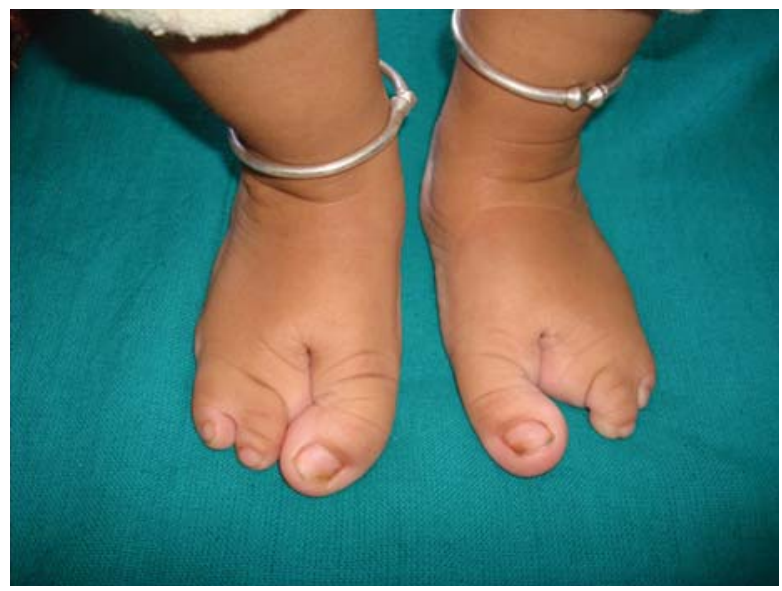

Fig 3: Feet

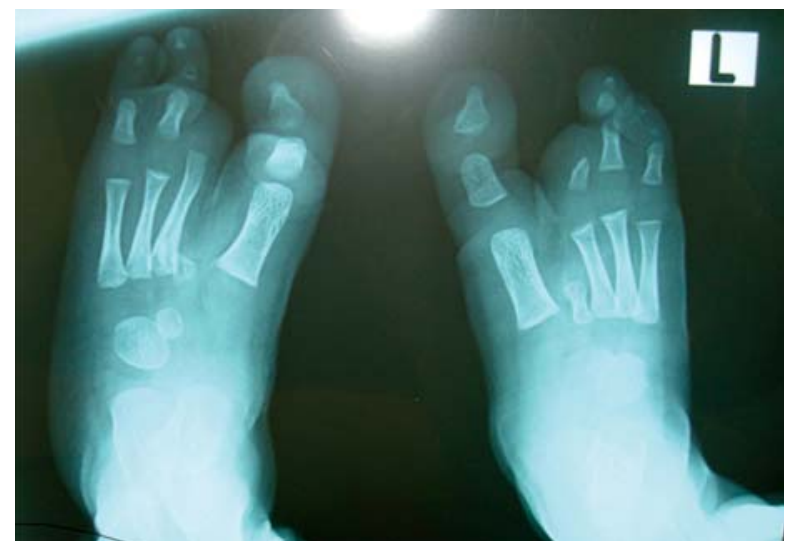

Fig 5: X-ray feet

X-Ray of the foot showed the presence of calcaneum, talus, cuboid and cuneiform with short $2^{\text {nd }}$ metatarsal bone. $3^{\text {rd }}$ proximal phalynx was present on the left but absent on the right. $2^{\text {nd }}$ and $3^{\text {rd }}$ toe were absent (Fig-5).

\section{Discussion}

Ectrodactyly, also known as Lobster claw deformity or split-hand/foot malformation is a congenital malformation of limbs and was first described in 1936

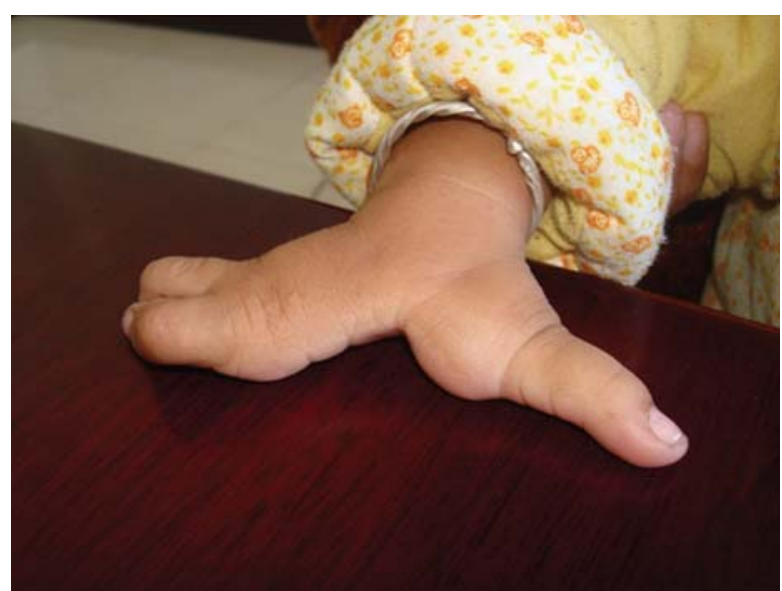

Fig 2: Right hand

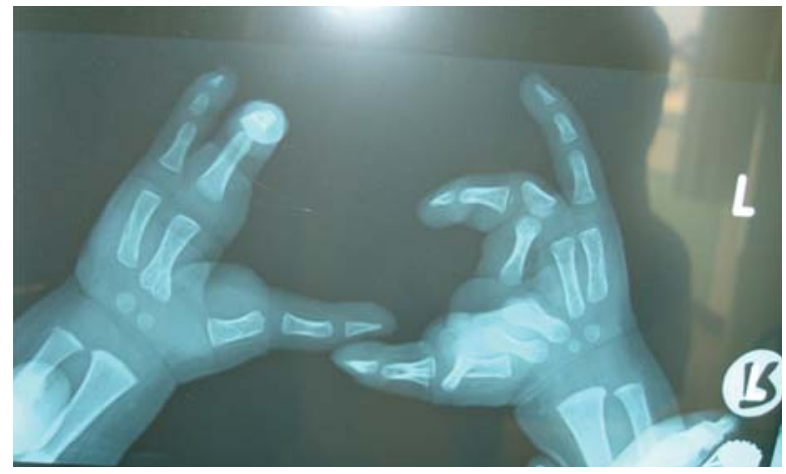

Fig 4: X-ray both hands

[1-3]. Its incidence is 1 per 90,000 live births with no sex predilection ${ }^{4}$

A deep median cleft of the hands and feet occurs as a result of the absence of the central digital rays ${ }^{5}$. The hands and feet appear split into two halves with aplasia/or hypoplasia of the phalanges, metacarpals and metatarsals. Variants of this anomaly include the number of missing digits and degree of fusion of the remaining digits.

Two modes of expression exist for SHFM, including an isolated Nonsyndromic form limited just to the limbs and Syndromic expression involving other anomalies such as tibial aplasia, mental retardation, ectodermal dysplasia, craniofacial findings, orofacial clefting and deafness ${ }^{6}$.

Ectrodactyly can be caused by a large number of human gene defects like deletions, translocations and inversions in chromosome $7(7 q)^{7}$.

The most common mode of inheritance is autosomal dominant while autosomal recessive and X-linked forms occur more rarely ${ }^{8}$. 
Although most cases of SHFM are sporadic, familial forms exist with predominantly autosomal dominant inheritance ${ }^{5}$. Syndromic SHFM has variable degrees of expression. The non-syndromic SHFM limited to the hands and feet, usually follows the pattern of inheritance of a regular autosomal dominant gene with a high penetrance ${ }^{9}$.

Parents should be counseled for the possibility of recurrence of the disease in the future siblings. Antenatal diagnosis by Ultrasonography is important. Ultrasonography is not only important for antenatal diagnosis of developmental defect of fetal limb, but also excludes the potentially serious associated anomalies ${ }^{6}$. A 3-dimensional sonographic images of this anomaly confirm the diagnosis ${ }^{6,10}$. Most cases of isolated ectrodactyly do not require surgical intervention, and most individuals with isolated ectrodactyly live normal lives with modest functional impairment of the hands ${ }^{11}$.

Ectrodactyly can be treated surgically by using prosthetics in order to improve the function and appearance.

\section{References}

1. Arbués J, Galindo A, Puente JM, Vega MG, Hernandez $M$, de la Fuente P. Typical isolated ectrodactyly of hands and feet: early antenatal diagnosis. J Matern Fetal Neonatal Med 2005; 17:299-301.

2. O'Brien KE, Shorrock J, Bianchi DW. Prenatal diagnosis of acro-dermato-ungual-lacrimal-tooth syndrome, a dominantly inherited ectrodactyly. J Ultrasound Med 2002;21:921-925.
3. Chuangsuwanich $T$, Sunsaneevithayakul $P$, Muangsomboon K, Limwongse C. Ectrodactylyectodermal dysplasia-clefting (EEC) syndrome,a case report and review of the literature. Prenat Diagn 2005; 25:210-215.

4. Jindal G, Parmar VR, Gupta VK. Ectrodactyly/ split hand feet malformation. Indian J Hum Genet 2009;15:140-2.

5. Duijf $P$, van Bokhoven H, Brunner HG. Pathogenesis of split-hand/split-foot malformation. Hum $\mathrm{Mol}$ Genet 2003;12:R51-R60.

6. Pinette M, Garcia L, Wax JR, Cartin A, Blackstone J. Familial ectrodactyly. J Ultrasound Med 2006; 25:1465-7.

7. Wieland, I., et al. (2004). "Refinement of the deletion in $7 q 21.3$ associated with split hand/ foot malformation type 1 and Mondini dysplasia". J Med Genet 2004; 41(5: e54. doi:10.1136/ jmg.2003.010587.

8. Pascal, H.G. et al. (2003). "Pathogenesis of splithand/split-foot malformation". Hum Mol Genet 2003;12(1): R51-R60. doi:10.1093/hmg/ddg090.

9. Zlotogora J. On the inheritance of the split hand/ split foot malformation. Am J Med Genet 1994; 53:29-32.

10. Kohler R, Sousa P, Jorge CS. Prenatal diagnosis of the ectrodactyly, ectodermal dysplasia, cleft palate syndrome. J Ultrasound Med 1989;8:337-339.

11. Lewis, Thomas (1908). "The Inheritance of Deformities". Brit Med J 1908;2(2481):166-173. doi:10.1136/bmj.2.2481.166

\section{How to cite this article?}

Keyal K, Joshi BG, Pandey R, Shrestha BM. Ectrodactyly: A rare anomaly of limbs. J Nepal Paediatr Soc 2011;31(3):235-237. 